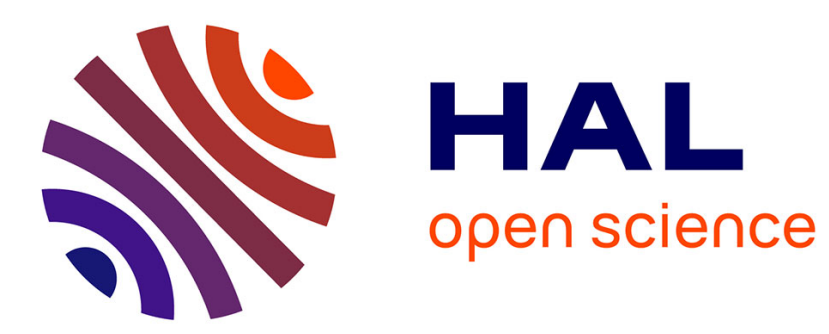

\title{
First metagenomic survey of the microbial diversity in bioaerosols emitted in waste sorting plants
}

Jodelle Degois, Frédéric Clerc, Xavier Simon, Cyril Bontemps, Pierre Leblond, Philippe Duquenne

\section{- To cite this version:}

Jodelle Degois, Frédéric Clerc, Xavier Simon, Cyril Bontemps, Pierre Leblond, et al.. First metagenomic survey of the microbial diversity in bioaerosols emitted in waste sorting plants. Annals of Work Exposures and Health, 2017, 61 (9), pp.1076 - 1086. 10.1093/annweh/wxx075 . hal-01655252

\section{HAL Id: hal-01655252 \\ https://hal.univ-lorraine.fr/hal-01655252}

Submitted on 19 Dec 2017

HAL is a multi-disciplinary open access archive for the deposit and dissemination of scientific research documents, whether they are published or not. The documents may come from teaching and research institutions in France or abroad, or from public or private research centers.
L'archive ouverte pluridisciplinaire HAL, est destinée au dépôt et à la diffusion de documents scientifiques de niveau recherche, publiés ou non, émanant des établissements d'enseignement et de recherche français ou étrangers, des laboratoires publics ou privés. 


\title{
First metagenomic survey of the microbial diversity in bioaerosols emitted in waste sorting plants
}

\author{
Jodelle Degois ${ }^{1}$, Frederic Clerc ${ }^{1}$, Xavier Simon ${ }^{1}$, Cyril Bontemps ${ }^{2}$, Pierre \\ Leblond ${ }^{2}$, Philippe Duquenne $e^{1}$
}

${ }^{1}$ Department of pollutant metrology - Institut National de Recherche et de Sécurité (INRS), Vandœuvre-lès Nancy, 54500, France

${ }^{2}$ Université de Lorraine, Institut National de la Recherche Agronomique, Dynamique des Génomes et Adaptation Microbienne (DynAMic), UMR INRA 1128, Nancy, 54000, France

\begin{abstract}
Waste sorting activities are source of occupational bioaerosol exposures that are associated with several health disorders. New analytical tools, based on next generation sequencing (NGS) technologies, provide powerful methods to assess the microbial composition of bioaerosols. The objectives of the study were (1) to assess the feasibility and the repeatability of NGS based biodiversity measurements and (2) to study the microbial biodiversity using NGS in bioaerosols emitted in a waste sorting plant (WSP). Three stationary parallel samples were collected in a sorting cabin using closed-face cassettes equipped with polycarbonate membranes. Bacterial and fungal diversity was assessed by sequencing $16 \mathrm{~S}$ and $18 \mathrm{~S}$ rDNA genes using either Illumina sequencing or 454 pyrosequencing methods. At sampling point, airborne bacteria were dominated by Proteobacteria, Firmicutes and Actinobacteria with prevailing genera assigned to unclassified Enterobacteriaceae, Staphylococcus, Acinetobacter, Leuconostoc, Pseudomonas and Lactobacillus. Airborne fungi were dominated by Ascomycota with prevailing genera assigned to Penicillium, Aspergillus, Rhizopus,


Wallemia and Hemicarpenteles. The NGS biodiversity measurements revealed a higher biodiversity bioaerosols that previously reported for WSP in studies carried out using culture methods followed by identification of microorganisms. These results provide the first survey about taxonomic biodiversity in bioaerosols from WSPs using high-throughput sequencing.

Keywords: Waste sorting plant, Bioaerosol, Occupational exposure, Biodiversity, Nextgeneration sequencing, 16S rDNA Illumina sequencing, 18S rDNA 454 pyrosequencing 


\section{Introduction}

Household waste sorting activities are source of occupational exposure to bioaerosols including bacteria, fungi, endotoxins, (1,3)- $\beta$-D-glucans as well as inhalable dust (Breum et al., 1999 ; Gladding et al., 2003 ; Hebisch and Linsel, 2012 ; Schlosser et al., 2015). Studies carried out in waste sorting plants (WSP) reported health disorders such as non-allergic symptoms (chronic bronchitis and mucous membrane irritations) as well as allergic symptoms (allergic asthma, allergic rhinitis and hypersensitivity pneumonitis) among the population of WSP workers exposed to bioaerosols (Gladding et al., 2003; Ivens et al., 1997; Perez et al., 2006).

Bacteria, fungi and viruses found in bioaerosols at the workplaces, as well as the associated microbial compounds such as endotoxins, $(1,3)-\beta$-D-glucans, mycotoxins and allergens, were presented as the possible causative agents of occupational diseases (Douwes et al., 2003 ; Eduard et al., 2012). However, the complex composition of bioaerosols still prevents identifying the specific microbial agents responsible for health effects as well as their precise role in symptoms. As a consequence, the dose-response relationships have not yet been established for most of non-infectious airborne microorganisms and no occupational exposure limit values are available. Thus, defining the precise composition of the bioaerosols to which employees are exposed to would provide a better understanding of biological risks at the workplaces.

So far, the microbial biodiversity data published in (WSP) were obtained by cultivation of microorganisms on nutrient media prior to identification. The corresponding studies found that the dominant fungi belonged to Penicillium sp., Aspergillus sp., Cladopsorium sp. (Breum et al., 1999; Lehtinen et al., 2013; Tolvanen, 2001; Viegas et al., 2014). However, the culture method underestimates the total number of microorganisms in samples as dead cells 
and microorganisms at viable but non cultivable (VBNC) state due to the selecting effect of culture media and cultivation conditions (Amann et al., 1995; Heidelberg et al., 1997). Thus, the cultured based biodiversity measurements previously performed in WSP surely have underestimated the real microbial taxon richness.

Advances in molecular biology and Next-generation sequencing (NGS) provided new powerful methods for biodiversity studies. These molecular methods were already used in bioaerosol studies carried out in different occupational environments such as composting facilities (Partanen et al., 2010), wastewater treatment plants (Lin et al., 2014), and swine houses (Kumari and Choi, 2015). NGS overcame the limitations of culture based methods and provided useful data (greater observed biodiversity, detection of non-preponderant taxa etc.) for a better understanding of the microbial communities to which workers may be exposed. However, the NGS have also some limitations due to the DNA extraction efficiency, PCR biases or the short size of the amplified DNA fragments which do not allow the identification at the species level. Nevertheless, the NGS could provide additional information as compared to culture-based methods (Yoo et al., 2017). To date, metagenomics methods were not applied to investigate the microbial biodiversity found in WSP. The aims of the present study were (1) to assess the feasibility and the repeatability of NGS based biodiversity measurements in WSP and (2) to apply this method in order to study the bioaerosol microbial biodiversity in bioaerosols emitted in a WSP.

\section{Materials and methods}

\section{Description of the WSP}

Bioaerosol biodiversity was assessed in July 2014 in a French WSP sorting journal newspapers, papers, cardboards, food packaging and other sorting wastes (4000 tons per 
month). The WSP employed about 50 workers mainly dedicated to manual sorting in three cabins.

\section{Bioaerosol sampling}

Three stationary parallel samples were collected in a cardboard sorting cabin (SC) and one outdoor reference (OR) sample was also collected at about $50 \mathrm{~m}$ upwind far from the WSP boundary to determine the background level. Bioaerosols were sampled with $37 \mathrm{~mm}$ closedface cassettes (CFC) equipped with a sterile polycarbonate filter (Nuclepore ${ }^{\circledR}, 0.8 \mu \mathrm{m}$ pore size) and a backing cellulose pad (Millipore ${ }^{\circledR}$, thick cellulose absorbent pad). The cassettes were connected to constant flow pumps (Bravo, Tecora, France) and sampling was performed at a flow rate of $10 \mathrm{~L} \cdot \mathrm{min}^{-1}$. The flow rate was calibrated before and after sampling using a flow meter (Mass Flowmeter 4040, TSI Inc., USA). Sampling devices were placed at $1.7 \mathrm{~m}$ above ground level and the sampling was conducted for five hours during the work shift. Temperature and relative humidity were monitored using a portable device (Thermohygrometer B6285C Pocket, Fischer, France) at the beginning and at the end of each sampling. Bioaerosol samples were transported to the laboratory during the day of sampling using a cold box and were then stored at $4^{\circ} \mathrm{C}$ until analysis. All samples were analyzed within 24 hours after being collected.

\section{DNA extraction}

A volume of $10 \mathrm{~mL}$ of a sterile solution $(0.01 \%$ Tween 80 in ultra-pure water) was introduced into the cassettes by the inlet. The cassettes inlets and outlets were closed with a cap and placed on a rocker (Heildolph ${ }^{\circledR}$, Multi-Reax shaker) at $2000 \mathrm{rpm}$ for $20 \mathrm{~min}$, at room temperature. DNA extraction was performed with $500 \mu \mathrm{L}$ of the subsequent elution solution with FastDNA $^{\circledR}$ SPIN kit for soil kit (MP Biomedicals, Illkirch, France) according to the manufacturer's instructions. The DNA concentration was measured using Nanodrop 2000c 
spectrophotometer (Thermo Fischer Scientific, Illkirch, France). Mean concentrations observed in all samples was $6.17 \pm 1.30 \mathrm{ng} . \mu \mathrm{L}^{-1}$. The DNA samples were stored at $-20^{\circ} \mathrm{C}$ until sequencing.

\section{DNA sequencing and sequence data analysis}

DNA purification, amplification, sequencing and reads analysis were achieved by INRA Transfert Environnement (Narbonne, France). Bacterial 16S rDNA gene (V4-V5 variable region) was amplified using the universal primers F-GTGYCAGCMGCCGCGGTA and RCCCCGYCAATTCMTTTRAGT. The universal primers used for Eukaryota DNA amplification were w553 CTTTCCCTACACGACGCTCTTCCGATCTGCGGTAA TTCCAGCTCCAA and w554 GGAGTTCAGACGTGTGCTCTTCCGATCTTTGGCAAAT GCTTTCGC, targeting the V1 variable region of Eukaryota 18S rDNA. Each PCR mixture consisted of: $5 \mu \mathrm{L}$ of DNA template, $4 \mu \mathrm{L}$ of dNTPs $(25 \mathrm{mM}), 1 \mu \mathrm{L}$ of each primer $(100$ ng. $\mu \mathrm{L}^{-1}$ ), and $0.5 \mu \mathrm{L}$ of Taq polymerase in a total volume of $50 \mu \mathrm{L}$. . A PCR cycle was 2 min at $95^{\circ} \mathrm{C}$ (denaturation step), $1 \mathrm{~min}$ at $56^{\circ} \mathrm{C}$ or $65^{\circ} \mathrm{C}$ for $18 \mathrm{~S}$ or $16 \mathrm{~S}$ rDNA amplification respectively (annealing step) followed by $1 \mathrm{~min}$ at $72^{\circ} \mathrm{C}$ (elongation step). Bacterial $16 \mathrm{~S}$ rDNA was sequenced using MiSeq technology (Illumina, San Diego, USA). The Eukaryota 18S rDNA was sequenced using GS-FLX pyrosequencer (454 Life Sciences, Branford, CT, USA).

The preprocessing of sequence analysis was performed using a Mothur pipeline version 1.33.2 (Schloss et al., 2009) developed by INRA Transfert Environnement. After trimming and denoising, barcodes, primers and homopolymers longer than $8 \mathrm{pb}$ were removed. Chimera were detected and deleted using UNCHIME (Edgar et al., 2011) executed in Mothur. Reads with 100 per cent of identity were clustered into a unique sequence. Then, sequences were clustered into Operational Taxonomic Units (OTU) at a threshold of $97 \%$ sequence 
similarity. Bacterial taxonomy assignments were performed using the Mothur platform ("average" method) using SILVA database. The ten dominant eukaryotic OTUs were identified at the genus rank at 95\% sequence similarity using BLASTn algorithm in Genbank (NCBI database; https://blast.ncbi.nlm.nih.gov).

The Shannon's index, H', was calculated with the following formula: $\mathrm{H}^{\prime}=-\sum \mathrm{Pi} \mathrm{x} \ln \mathrm{Pi}$, where $\mathrm{Pi}=\mathrm{Ni} / \mathrm{N}, \mathrm{Ni}$ is the OTU number in a genus and $\mathrm{N}$ is the total OTU number. The Simpson's index, $\mathrm{D}$, was calculated with the following formula: $\mathrm{D}=\sum(\mathrm{Ni} \times(\mathrm{Ni}-1) / \mathrm{N} \times(\mathrm{N}-1))$. The Simpson's index measures the probability that two OTU chosen randomly will be associated with the same taxon (in that case the genus). The more the index value is near the value 0 , the more the taxa are present in different proportions. On the contrary, the more the index value is near 1 , the more the taxa are present in the same proportion. The values of Shannon's index are between 0 and S, the total taxa number and values of Simpson's index are between 0 and 1.

\section{Repeatability of the biodiversity measurement process}

The repeatability of the bioaerosol measurement process was assessed on the $16 \mathrm{~S}$ rDNA OTUs found in the three parallel replicate samples collected in the SC. Simple descriptive statistics of the proportions of each phylum were calculated. The arithmetic mean (AM) and the arithmetic standard deviation (SD) allowed computing the coefficient of variation (SD / $\mathrm{AM})$. The average coefficient of variation (CV) of all phyla was also computed and assumed as representing the degree of similarity between the three samples. The AM and the CV were also calculated for Shannon's and the Simpson's indexes from the replicates samples. The calculation of simple descriptive statistics of the proportions of each phylum revealed CV values below $10 \%$ (data not shown). For example, the proportion of Proteobacteria was 34.57 $\%$ in SC1, $34.37 \%$ in SC2 and $33.04 \%$ in SC3 which corresponds to a CV(Proteobacteria) 
equals $2 \%$. Furthermore, the average coefficient of variation of all phyla was $9 \%$. Descriptive statistics calculated from the replicates samples regarding the proportions of phyla revealed CV values below $10 \%$. The calculated CV for the Shannon's and the Simpson's indexes were below $6 \%$. These statistics suggest that bacterial and Eukaryota biodiversity can be assumed as repeatable.

\section{Results}

The biodiversity was estimated in the sorting cabin (SC) (three replicates) and compared to that of the outdoor reference $(\mathrm{OR})$.

\section{Environmental and working conditions}

The temperatures monitored in July 2014 in the $\mathrm{SC}$ and in the $\mathrm{OR}$ were $28^{\circ} \mathrm{C}$ and $29^{\circ} \mathrm{C}$, respectively. The relative humidity of the air at the same points was $51 \%$ and $46 \%$ respectively. During the sampling, the working activity in the WSP was continuous and regular and no particular malfunction such as stopping in the sorting line occurred. Two operators were working in the cardboard sorting cabin.

\section{Assessment of biodiversity using deep sequencing}

The outlines of high-throughput sequencing data obtained in the study are given in Table 1 . For bacterial 16S rDNA, Illumina sequencing provided about 78,600 reads in the OR sample and between 69,600 and 100,000 reads in the SC samples (Table 1). This corresponds to 581 OTU in the OR sample and between 842 and 1,233 OTU in the SC samples. More than $80 \%$ of the sequences were assigned to bacterial OTUs in all the samples. The Shannon's indexes were from 6.41 to 6.60 in the SC samples and 4.24 in the OR one (Table 1). In the three replicates, the mean Shannon's index was 6.48 $\pm 0.10(\mathrm{CV}=1.61 \%)$. The Simpson's indexes were 0.1 in the $\mathrm{OR}$ and 0.02 in the SC samples, indicating that dominant bacterial genera 
were present in the two areas. For Eukaryota $18 \mathrm{~S}$ rDNA, 454 pyrosequencing provided about 6,600 reads for in the OR sample and between 14,546 and 21,206 reads for the SC samples (Table 1). This corresponded to 15 OTUs in the OR sample and about 40 OTUs in the SC. The Shannon's indexes were 1.83 in the OR and $1.25 \pm 0.07(\mathrm{CV}=5.60 \%)$ in the SC. The Simpson's indexes were 0.25 in the OR and about 0.45 in the SC.

\section{Taxonomic diversity of airborne bacterial communities}

The phylogenetic taxonomy analysis assigned more than $80 \%$ of the reads at the phylum rank, $70 \%$ at the family rank and $60 \%$ at the genus rank (see supplementary data Table S1).

The four main phyla found in bioaerosol samples were Actinobacteria, Firmicutes, Proteobacteria and Bacteroidetes (Figure 1). They accounted for about $80 \%$ of the total reads for the SC and $83 \%$ for the OR. Unidentified $16 \mathrm{~S}$ sequences represented $17 \%$ and $12 \%$ in the SC and in the OR, respectively. The other found phyla belonged to Chloroflexi, Cyanobacteria, Deinococcus-Thermus and Planctomycetes and account individually for less that $2.5 \%$ of the total reads. Actinobacteria, Firmicutes and Bacteroidetes showed higher proportions in the SC than in the OR (Figure 1). Indeed, Actinobacteria and Firmicutes appeared to be more preponderant in bioaerosols that were emitted in the SC. Proteobacteria were the predominant phylum in all samples and in higher proportion in the OR sample.

At the family rank (see supplemental data Table S2), the specific richness was higher in the SC (78 families) than in the OR (59 families) samples. Most of these families belonged to the Proteobacteria phylum (26 in the SC and 23 in the OR) which accounted for $32 \%$ of the reads in the SC and $58 \%$ in the OR. In addition, $25 \%$ of the reads were assigned to Firmicutes families in the SC whereas they only account for $6.3 \%$ in the OR. The 20 main families found in the sorting cabin are represented in the Figure 2. The proportion of these families was between $9.34 \%$ (Entorobacteriaceae) and $0.83 \%$ (Aerococcaceae) in the SC and accounted 
for $57 \%$ of the bacterial reads. Others predominant families were Staphylococacceae $(6.0 \%)$ and Pseudomonadaceae (5.0\%).

The analysis of sequences at the genus rank revealed 112 bacterial genera in the SC samples (Table S3). Dominant airborne bacteria in SC samples were unclassified Enterobacteriaceae (8.38 \%), Staphylococcus (5.63 \%), Acinetobacter (4.48 \%), Leuconostoc (3.07 \%), Pseudomonas (2.99\%), Lactobacillus (2.27\%), unclassified Planococcaceae $(2.15 \%)$ and Brevibacterium $(2.04 \%)$. The analysis of sequences at the genus rank also highlighted differences between SC and OR. In the SC, 11 genera were observed with a 20-fold higher than in the OR (see Table S3). These 11 genera accounted for $25 \%$ ( $<1 \%$ in the OR) of total bacterial reads and belonged to Staphylococcus, Enterococcus, Streptococcus, Lactobacillus, Lactococcus, Leuconostoc and Brevibacterium.

\section{Biodiversity of airborne Eukaryota communities}

The phylogenetic taxonomy analysis of $18 \mathrm{~S}$ rDNA sequences revealed the occurrence of living organisms belonging to the Fungi and the Plantae kingdoms and assigned more than 99 $\%$ of the reads at the phylum rank in the 4 collected samples (Table S1).

In SC samples, Fungi represented $99.4 \%$ of the reads and the remaining ones were assigned to Plantae $(0.12 \%)$ or remained unidentified $(0.44 \%)$. The three main fungal phyla found in bioaerosol samples were Ascomycota $(91.1 \%)$, an early diverging fungal lineage [Mucor and Rhizopus] (4.64 \%) and Basidiomycota (3.70 \%). Twenty two fungal genera were found. The ten dominant fungal OTUs represented $98.5 \%$ of eukaryotic OTUs with a predominance of the Penicillium, Aspergillus and Rhizopus genera (Figure 3.a). Wallemia was the dominant Basidiomycota genus found in SC samples.

In the OR sample, Fungi and Plantae represented $70.0 \%$ and $29.9 \%$ of the reads, respectively, and the remaining ones were unidentified $(0.1 \%)$. The two fungal phyla found 
in bioaerosol samples were Ascomycota (59.0\%) and Basidiomycota (11.0\%); fungi belonging to the early diverging fungal lineage were not found. The dominant outdoor fungal genera were Cladosporium (45.2\%), unidentified Ascomycota (8.3\%), Oligoporus $(7.3 \%)$, unidentified Basidiomycota (3.6 \%) and, Penicillium (3.5\%). Biodiversity also consisted of others Eukaryota such as Viridiplantae (Figure 3.b).

\section{Discussion}

\section{Bacterial and fungal biodiversity in the WSP}

Very few data have been published regarding the biodiversity of airborne bacterial and fungal particles in industrial plants sorting household waste. Furthermore, the available biodiversity data were obtained by culture of microorganisms followed by macroscopic and/or microscopic identification as well as biochemical identification. Thus, we have found no equivalent results in previous published studies to which our findings could be compared to.

The first analysis of NGS data indicates a higher biodiversity in samples collected in the SC as compared with the outdoor one. Furthermore, biodiversity indexes showed that bacterial biodiversity was higher than Eukaryota biodiversity. Fungal genera were more present in equi-proportion than bacterial genera.

For airborne bacteria, in a plant located in Finland where household wastes were sorted, bioaerosols were dominated by unidentified Gram-positive and Gram-negative cultivated bacteria and by bacteria belonging to Pseudomonas, Bacillus and Micrococcus (Rahkonen, 1992). In a Danish paper sorting plant, Breum et al., found that airborne cultivated bacteria were dominated by Gram-positive bacteria, including Staphylococcus and Bacillus species, and Actinomycetes (Breum et al., 1999). Cultivated bacteria belonging to Staphylococcus, Bacillus, Streptococcus, or Micrococcus genera were also found in others studies carried during landfill (Breza-Boruta, 2012), glass sorting (De Vasconcelos Pinto et al., 2015) and 
waste collection (Nielsen et al., 1995; Madsen et al., 2016). In these studies, bacterial identification was usually achieved on a limited number of colonies and using Gram staining, metabolic tests, gas chromatography or mass spectrometry after cells culture. Data from previous biodiversity studies in the waste treatment sector provided similarities with our results regarding dominant bacterial taxa such as Staphylococcus, Pseudomonas, and actinomycetes. They also provided differences as Bacillus was not found in great portion in our study as compared previous published ones. Differences found in bacterial taxa might be explained by the methods used for assessing biodiversity as well as the geographic and climatic changes in bioaerosol biodiversity (Smets et al., 2016). Furthermore, due to the limits of the sequencing methods, the bacterial biodiversity could not be assessed at the species level in the study. Indeed, the DNA fragments sequenced by the Illumina technology were too short and the genetic target was too preserved to allow identification at the species level with a good accuracy. So, the NGS provided insufficient information for an accurate bacterial risk evaluation. To assess the bacterial risk, others methods such as the identification of cultured bacteria using MALDI-TOF could be used in addition with the sequencing.

For airborne fungi, findings from our study are in agreement with previous published studies for similar activities. Indeed, airborne cultivated fungi belonging to the Penicillium genus was found prevalent during sorting of household waste, while the Aspergillus, Rhizopus, Cladosporium, Geotrichum, and Chrysonilia genera were also common (Breum et al., 1999; Tolvanen, 2001; Tolvanen and Hänninen, 2006; Malta-Vacas et al., 2012; Lehtinen et al., 2013; Viegas et al., 2014). Aspergillus fumigatus was also detected in bioaerosol samples collected in WSP by the culture method (Tolvanen, 2001; Tolvanen and Hänninen, 2006) as well as by PCR (Malta-Vacas et al., 2012). The genus Penicillium was also found to be dominant in other studies carried during out glass sorting (De Vasconcelos Pinto et al., 2015) and during waste collection (Madsen et al., 2016). In the latter study, the authors found 11 
Penicillium species as $P$. brevicompactum, $P$. camemberti or $P$. chrysogenum after identification of colony using MALDI-TOF MS. They also observed 6 Aspergillus species inclunding A. nidulans, A. niger and A. versicolor. This suggests that a substantial biodiversity can be found at the species level in bioaerosols emitted during waste collection. Such a biodiversity is expected in waste soring plants, however, as for the bacterial biodiversity, the methods used in the present study did not allow identifying the fungal sequences at the species level.

The NGS biodiversity data from the present study revealed a far more important diversity than expected from the culture data as 112 different bacterial genera. In others studies, the authors observed from 20 bacterial genera and up to 38 bacterial species using culture-based methods (Rahkonen, 1992; Nielsen et al., 1995; Breum et al., 1999; De Vasconcelos Pinto et al., 2015; Madsen et al., 2016). The fungal diversity was more important than expected from culturing approach since 22 different genera were identified in our study versus only 2 to 8 in previous reports (Breum et al., 1999; Tolvanen, 2001; Tolvanen and Hänninen, 2006; MaltaVacas et al., 2012; Lehtinen et al., 2013; Viegas et al., 2014). Thus, NGS provides a deeper accuracy of the types of microorganisms to which WSP workers might be exposed. To our knowledge, these results are the first report of bacterial and fungal biodiversity survey, using a metagenomics approach, published about bioaerosol emitted in waste sorting plant.

\section{Cardboard sorting cabin vs. Outdoor}

The first analysis of high-throughput sequencing data indicates a higher biodiversity in samples collected in the WSP than in the OR. The dominant bacterial genera were different in the $\mathrm{OR}$ and in the SC and the composition of bioaerosols were different in the two areas whatever the taxon rank considered. Differences in biodiversity were also observed between OR and SC samples; the outdoor Eukaryota community was specifically dominated by 
Cladosporium and Plantae. Such differences were already reported regarding the fungal community (Malta-Vacas et al., 2012; De Vasconcelos Pinto et al., 2015). Our findings showed that WSP workers are exposed to a specific bioaerosol at their workstation.

\section{Significance of NGS biodiversity findings}

Several bacterial genera found in the present study were associated with human or animal skin, mucous membrane or intestinal tract such as, Staphylococcus (Schleifer and Bell 2009), Enterococcus (Svec and Devriese 2009) and Streptococcus (Whiley and Haride 2009). Bacteria from dairy milk or meat were also found such as Lactobacillus (Hammes and Hertel 2009), Lactococcus (Teuber 2009), Leuconostoc (Holzapfel et al. 2009), and Brevibacterium (Brennan et al. 2002). Bacterial biodiversity in the SC appears related to the occupational activities due to the origin of waste (domestic environment) as well as the presence of workers. This might explain the differences observed between the two sampling area.

The fungal genera found in our study include species that were associated with allergenic symptoms, opportunistic infection in immunosuppressed patients (Aspergillus fumigatus) or known as MVOC or mycotoxin producers (Fischer et al. 2000). The phylogenetic taxonomy analysis of $18 \mathrm{~S}$ rDNA sequences allowed highlighting the occurrence of slow growing fungi belonging to the Stachybotrys and the Wallemia genera. These genera include harmful species that were almost never cited in previous works. Thus, culture based methods provide essential information, but they do not allow a global characterization of Eukaryota biodiversity. This confirms that NGS may provide a new view regarding the types of microorganisms to which WSP workers might be exposed to.

\section{Limits and perspectives of the study}

The present study was carried out with a limited number of samples and only three occupational bioaerosols and one reference were analyzed. This is not enough to draw 
definitive conclusion about the exposure of workers to microorganisms at the sorting plant. Indeed, due to the complexity of the bioaerosols composition and to confirm the difference between the sorting cabin and the outdoor reference, additional samples need to be collected in order to confirm these first results of biodiversity in a waste sorting plant. Data analysis showed that the Simpson's and Shannon's indexes were very close among the three replicates. Furthermore, the proportions of bacterial families found in the WSP bioaerosol appeared in the same range from a sample to another one. This suggests that the biodiversity measurement process is repeatable but additional statistical analyses are needed to comfort this. The study shows the usefulness of NGS based biodiversity measurements for occupational hygiene purposes in WSP but additional research is required to investigate more precisely the microbial composition of bioaerosols in this environment. Especially, studies are needed with more numerous bioaerosol samples collected in different WSP, at different working area in WSP and also at different moment of the year. The NGS is a qualitative method, to get a better understanding of the microbial exposure; the microbial concentration must be assessed using molecular biology methods such as qPCR or culture-based ones.

In the study, the $18 \mathrm{~S}$ rDNA what used as target gene for the assessment of fungal biodiversity in bioaerosols. This approach reveals that Fungi were the most Eukaryota communities in the sorting cabin. Furthers studies, should focus on fungal biodiversity using the ITS (internal transcribed spacer) barcode which give a better taxonomic resolution for Fungi (Schoch et al., 2012).

NGS technologies have also some biases that were not addressed in our investigation. The metagenomics DNA must be of good quality to allow its sequencing. Biodiversity studied by NGS is also affected by the DNA extraction efficiency. Indeed, some microbial species can be preferably extracted depending on the DNA extraction method (Haugland et al., 1999). In addition, errors were reported due to PCR biases in the sequences library preparation and to 
data analysis (sequences alignment). Illumina technologies provide short reads (150 pb for HiSeq and $250 \mathrm{pb}$ for Miseq), these shorts reads are aligned with reference sequences to get a match probability. The incorrect annotation of reference sequences in the database can introduce mistakes in data analysis (Nilsson et al., 2006, Yamamoto et al., 2014). Because of these facts, the biodiversity, in our study, can only be assessing at the genus level (deeper assignment). But, an assessment of biodiversity at the species level is possible with an increase of the reads size using another sequencing technology as PacBio sequencing. Furthermore, a sequencing of the entire ITS region, rather than the ITS2 sequencing, can provide an accurate method to assess the fungal biodiversity at the species level (Yamamoto et al., 2014). Error factors due to NGS methods are sometimes not suspected by the users or difficult to suppress. Previous studies showed that bioinformatics steps can reduce the impact of these factors. (Bellemain et al., 2010; Ovaskainen et al., 2010; Gihring et al., 2012; van Dijk et al., 2014 ; O'Rawe et al., 2015). Biodiversity studied by NGS is also affected by the DNA extraction efficiency and as well as the accuracy annotation of the sequences in the data basis (Nilsson et al., 2006, Yamamoto et al., 2014). Nevertheless, NGS is a useful approach to describe microbial communities in occupational area, in addition to cells culture methods. To improve the biological risk evaluation, the colonies can be identified using MALDI-TOF MS for identification at the species level of the main culturable genera which has been demonstrated to provide complementary data as compared to Illumna sequencing (Madsen et al., 2015). The metagenomics approach makes it possible to assess the microbial diversity as never before by removing the limits of the microbial culturability biasing the previous biodiversity studies. On the other hand, if the sequencing showed a higher biodiversity at the genus level, it did not provide any information about the bacterial or fungal species present in the bioaerosols. In furthers studies, an identification of microbial colony could be performed in addition to the sequencing to get information about the microbial biodiversity at the species 
level. The use of metagenomics made it possible to describe for the first time the biodiversity of bioaerosol in WSP overcoming such culture bias and provided a finer description of bioaerosol composition that may be inhaled by exposed WSP workers.

\section{Conclusion}

In the present study, the bacterial and fungal abundance in bioaerosols from a WSP treating household waste were revealed for the first time using $16 \mathrm{~S}$ rDNA Illumina sequencing and $18 \mathrm{~S}$ rDNA 454 pyrosequencing methods, respectively. The results showed that the components of airborne microbial communities were assigned to 4 phyla and 112 genera for bacteria and to 3 phyla and 22 genera for fungi. In the WSP, airborne bacteria were dominated by Proteobacteria, Firmicutes and Actinobacteria with prevailing genera assigned to unclassified Enterobacteriaceae, Staphylococcus, Acinetobacter, Leuconostoc, Pseudomonas and Lactobacillus. Airborne fungi were dominated by Ascomycota with prevailing genera assigned to Penicillium, Aspergillus, Rhizopus, Wallemia and Hemicarpenteles.

The NGS biodiversity measurements performed in the present study revealed a higher biodiversity in WSP bioaerosols than the one previously reported in studies carried out using culture methods followed by identification of microorganisms. This suggests that NGS would provide a greater accuracy than culture based methods regarding the types of microorganisms to which WSP workers might be exposed to. Furthermore, different microbial communities were found in the sorting cabin as compare with the outdoor air, which support the hypothesis that biodiversity in bioaerosols emitted in the WSP maybe specific to waste sorting activities.

the biodiversity measurement process provided repeatable results. However, further studies based on a larger number of samples and other targeted genes (ITS, genes involved in microbial pathogenicity or in the expression of allergens etc.) are needed to confirm these 
primary results and to investigate the uncertainty of biodiversity measurements as well as the variation of airborne microbiomes in time and in space at occupational settings.

\section{ACKNOWLEDGEMENTS}

The authors would to kindly acknowledge Catherine Coulais and Véronique Koehler for their valuable technical assistance. 


\section{REFERENCES}

Amann R, Ludwig W, Schleifer K. (1995) Phylogenetic identification and in situ detection of individual microbial cells without cultivation. Microbiol Rev; 59:143-69.

Bellemain E, Carlsen T, Brochmann C, Coissac E, Taberlet P, Kauserud H. (2010) ITS as an environmental DNA barcode for fungi: an in silico approach reveals potential PCR biases. BMC Microbiol; 10:189-98.

Brennan NM, Ward AC, Beresford TP, Fox PF,Goodfellow M, Cogan TM. (2002) Biodiversity of the bacterial flora on the surface of a smear cheese. Appl Environ Microb; 68: 820-30

Breum NO, Würtz H, Midtgaard U, Ebbehøj N. (1999) Dustiness and bio-aerosol exposure in sorting recyclable paper. Waste Manage Res; 17:100-08.

Breza-Boruta B. (2016) The assessment of airborne bacterial and fungal contamination emitted by a municipal landfill site in Northern Poland. APR; 7:1043-52.

Breza-Boruta, B. (2012). Bioaerosols of the municipal waste landfill site as a source of microbiological air pollution and health hazard. Ecol Chem Eng A; 19: 851-62.

Cuadros-Orellana S, Rabelo Leite L, Smith A, Dutra Medeiros J, Badotti F, Fonseca PL, Vaz AB, Oliveira G,Góes-Neto A. (2013). Assessment of fungal diversity in the environment using metagenomics: a decade in review. Fungal Genet Biol; 3.

De Vasconcelos Pinto MJ, Veiga JM, Fernandes P, Ramos C, Gonçalves S, Lemos Vaz Velho MM, Guerreiro JS. (2015) Airborne microorganisms associated with packaging glass sorting facilities. J Toxicol Env Health; 78: 685-96.

Douwes J, Thorne P, Pearce N, Heederik D. (2003) Bioaerosol health effects and exposure assessment: progress and prospects. Ann Occ Hyg; 47: 187-200. 
Edgar RC, Haas BJ, Clemente JC, Quince C, Knight R. (2011) UCHIME improves sensitivity and speed of chimera detection. Bioinformatics; 27: 2194-200.

Eduard W, Heederik D, Duchaine C, Green BJ. (2012) Bioaerosol exposure assessment in the workplace: the past, present and recent advances. J Environ Monit; 14: 334-9.

Fischer G, Müller T, Schwalbe R, Ostrowski R, Dott W. (2000) Exposure to airborne fungi, MVOC and mycotoxins in biowaste-handling facilities. Int J Hyg Env Heal; 203:97-104.

Gihring TM, Green SJ, Schadt CW. (2012) Massively parallel rRNA gene sequencing exacerbates the potential for biased community diversity comparisons due to variable library sizes. Environ Microbiol; 14: 285-90.

Gladding T, Thorn J, Stott D. (2003) Organic dust exposure and work-related effects among recycling workers. Am J Ind Med; 43: 584-91.

Hammes WP, Hertel C. (2009) Volume three, the Firmicutes : Lactobacillus. In De Vos P, Garrity GM, Jones D, Krieg NR, Ludwig W, Rainey FA, Schleifer KH, Whitman WB, editors. Berguey's manual of systematic bacteriology: (Springer), 465-510. ISBN 9780387 950419.

Haugland RA, Heckman JL, Wymer LJ. (1999)Evaluation of different methods for the extraction of DNA from fungal conidia by quantitative competitive PCR analysis. J Microbiol Meth; 37: 165-176.

Hebisch R, Linsel G, (2012) Workers' exposure to hazardous substances and biological agents in recycling enterprises. Gefahrst Reinhalt Luft; 72: 163-69.

Heidelberg JF, Shahamat M, Levin M, Rahman I, Stelma G, Grim C, Colwell RR. (1997) Effect of aerosolization on culturability and viability of gram-negative bacteria. Appl Environ Microb; 63:3585-88.

Holzapfel WH, Bjorkroth JA, Dicks LMT. (2009) Volume three, the Firmicutes: Leuconostoc. In De Vos P, Garrity GM, Jones D, Krieg NR, Ludwig W, Rainey FA, Schleifer 
KH, Whitman WB, editors. . Berguey's manual of systematic bacteriology: (Springer), 62438. ISBN 9780387950419.

Ivens U, Ebbehøj N, Poulsen OM, Skov T. (1997) Gastrointestinal symptoms among waste recycling workers. Ann Agr Env Med; 4:153-57.

Kumari P, Choi H. (2015) Manure removal system influences the abundance and composition of airborne biotic contaminants in swine confinement buildings. Environ Monit Assess; 187: 1-10.

Lehtinen J, Tolvanen O, Nivukoski U, Veijanen A, Hänninen K. (2013) Occupational hygiene in terms of volatile organic compounds (VOCs) and bioaerosols at two solid waste management plants in Finland. Waste Manage; 33: 964-73.

Lin W, Yu Z, Zhang H, Thompson IP. (2014) Diversity and dynamics of microbial communities at each step of treatment plant for potable water generation. Water Res; 52: 21830.

Madsen A M, Zervas A, Tendal K, and Nielsen J L. (2015). Microbial diversity in bioaerosol samples causing ODTS compared to reference bioaerosol samples as measured using Illumina sequencing and MALDI-TOF. Environ Res; 140: 255-267.

Madsen AM, Alwan T, Ørberg, A, Uhrbrand K, Jørgensen MB. (2016) Waste workers’ exposure to airborne fungal and bacterial species in the truck cab and during waste collection. Ann Occup Hyg; 60: 651-68.

Malta-Vacas J, Viegas S, Sabino R, Viegas C. (2012) Fungal and microbial volatile organic compounds exposure assessment in a waste sorting plant. J Toxicol Env Health; 75: 1410-7.

Nielsen EM, Nielsen BH, Breum NO. (1995) Occupational bioaerosol exposure during collection of household waste. Ann Agr Env Med; 2: 53-59. 
Nilsson RH, Ryberg M, Kristiansson E, Abarenkov K, Larsson KH, Kõljalg U. (2006) Taxonomic reliability of DNA sequences in public sequence databases: a fungal perspective. PLoS ONE; 1: e59.

O’Rawe JA, Ferson S, Lyon GJ. (2015) Accounting for uncertainty in DNA sequencing data. Trends Genet, 31: 61-6.

Ovaskainen O, Nokso-Koivisto J, Hottola J, Rajala T, Pennanen T, Ali-Kovero H,

Miettinen O, Oinonen P, Auvinen P, Paulin L, Larsson KH, Mäkipää R. (2010) Identifying wood-inhabiting fungi with 454 sequencing - what is the probability that BLAST gives the correct species? Fungal Ecol; 3: 274-83.

Park D, Ryu S, Kim S, Byun H, Yoon C, Lee K. (2013) Airborne bacteria and fungi associated with waste-handling work. Int J Occup Env Heal; 19: 311-8.

Partanen P, Hultman J, Paulin L, Auvinen P, Romantschuk M. (2010) Bacterial diversity at different stages of the composting process. BMC Microbiol; 10:1-11.

Perez HR, Frank AL, Zimmerman NJ. (2006) Health effects associated with organic dust exposure during the handling of municipal solid waste. Indoor Built Environ; 15: 207-12.

Rahkonen, P. (1992) Airborne contaminants at waste treatment plants. Waste Manage Res; 10: 411-21.

Ramette, A. (2007) Multivariate analyses in microbial ecology. FEMS Microbiol Ecol; 62: $142-60$.

Schleifer KH, Bell JA. (2009) Volume three, the Firmicutes: Staphylococcus. In De Vos P, Garrity GM, Jones D, Krieg NR, Ludwig W, Rainey FA, Schleifer KH, Whitman WB, editors. Berguey's manual of systematic bacteriology (Springer), 392-421. ISBN 9780387 950419.

Schloss PD, Westcott SL, Ryabin T, Hall JR, Hartmann M, Hollister EB, Lesniewski, RA, Oakley BB, Parks DH, Robinson CJ, Sahl JW, Stres B, Thallinger GG, Van Horn DJ, Weber 
CF. (2009) Introducing mothur: open-source, platform-independent, community-supported software for describing and comparing microbial communities. App Environ Microb; 75: $7537-41$.

Schlosser O, Déportes IZ, Facon B, Fromont E. (2015) Extension of the sorting instructions for household plastic packaging and changes in exposure to bioaerosols at materials recovery facilities. Waste Manage; 46: 47-55.

Schoch CL, Seifert KA, Huhndorf S Robert V, Spouge JL, Levesque CA, Chen W. (2012)

Nuclear ribosomal internal transcribed spacer (ITS) region as a universal DNA barcode marker for Fungi. PNAS; 109: 6241-6.

Smets W, Moretti S, Denys S, Lebeer S. (2016) Airborne bacteria in the atmosphere: presence, purpose, and potential. Atmospheric Environment; 139: 214-21.

Svec P, Devriese LA. (2009) Volume three, the Firmicutes: Enterococcus In De Vos P, Garrity GM, Jones D, Krieg NR, Ludwig W, Rainey FA, Schleifer KH, Whitman WB, editors. Berguey's manual of sytematic bacteriology (Springer), 594-606. ISBN 9780387 950419.

Teuber M. (2009) Volume three, the Firmicutes: Lactococcus. In De Vos P, Garrity GM, Jones D, Krieg NR, Ludwig W, Rainey FA, Schleifer KH, Whitman WB, editors. Berguey's manual of systematic bacteriology (Springer), 711-22. ISBN 9780387950419.

Tolvanen OK. (2001) Airborne bio-aerosols and noise in a dry waste treatment plant in Pietarsaari, Finland. Waste Manag Res; 19: 108-14.

van Dijk EL, Jaszczyszyn Y, Thermes C. (2014) Library preparation methods for nextgeneration sequencing: tone down the bias. Exp Cell Res; 322: 12-20.

Viegas C, Gomes AQ, Abegão J, Sabino R, Graça T, Viegas S. (2014) Assessment of fungal contamination in waste sorting and incineration-case study in Portugal. J Toxicol Env Health; 77: 57-68. 
Whiley RA, Haride JM. (2009) Volume three, the Firmicutes: Streptococcus. In De Vos P, Garrity GM, Jones D, Krieg NR, Ludwig W, Rainey FA, Schleifer KH, Whitman WB, editors. Berguey's manual of systematic bacteriology (Springer), 655-710. ISBN 9780387 950419.

Yamamoto N, Dannemiller KC, Bibby Kyle, Peccia J. (2014) Identification accuracy and diversity reproducibility associated with internal transcribed spacer-based fungal taxonomic library preparation. Environ Microbiol; 16: 2764-76.

Yoo K, Lee T K, Choi E J, Yang J, Shukla S K, Hwang S-i, and J Park, (2017). Molecular approaches for the detection and monitoring of microbial communities in bioaerosols: A review. J Environ Sci; 51, 234-247. 


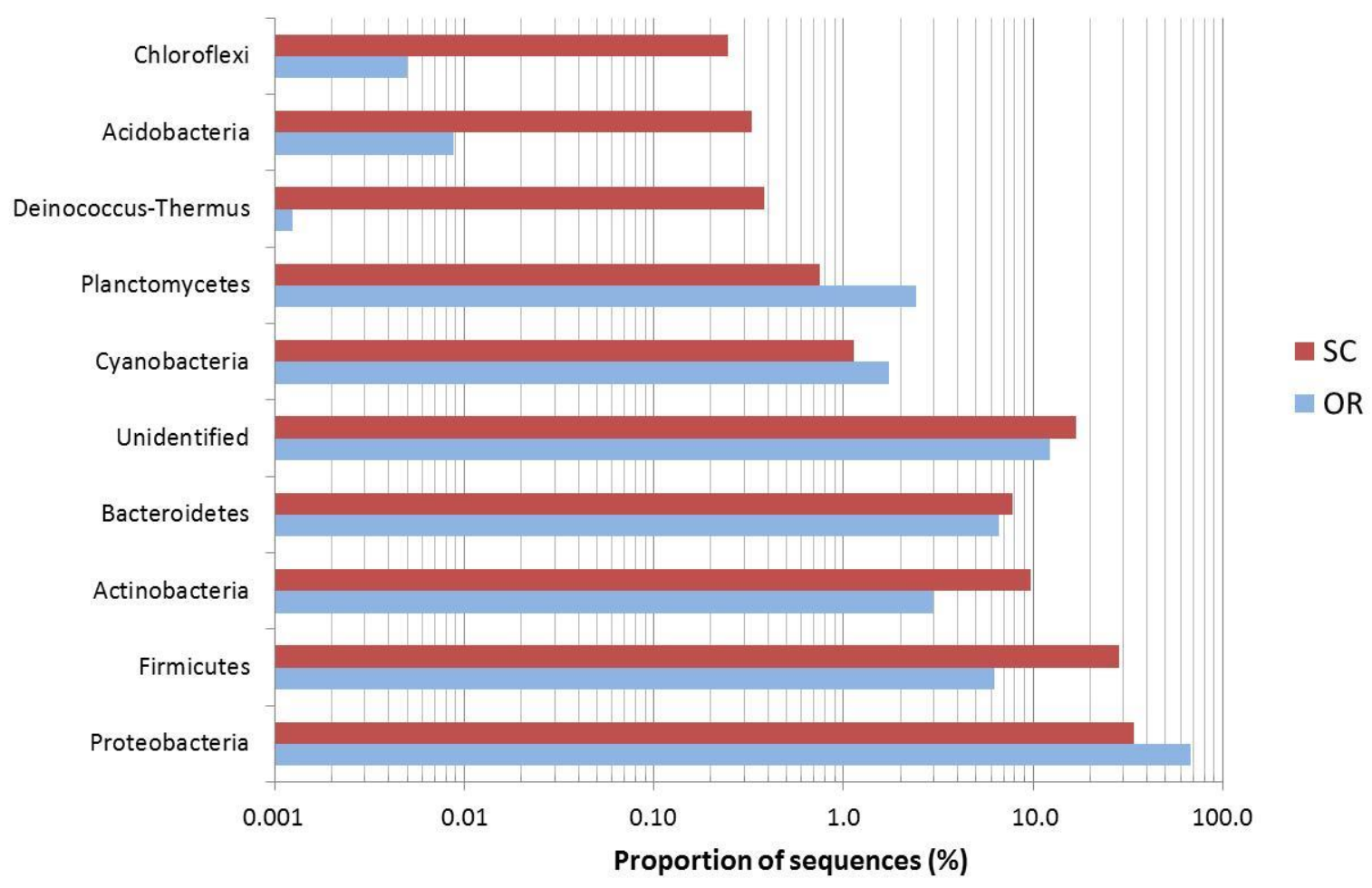

Figure 1: Bacterial biodiversity at the phylum Rank in bioaerosols from the WSP. Bioaerosol samples were collected in the Sorting Cabin (SC) and in the Outdoor Reference (OR). For practical reasons, only the mean of sequencing data from SC1, SC2 and SC3 are presented. 


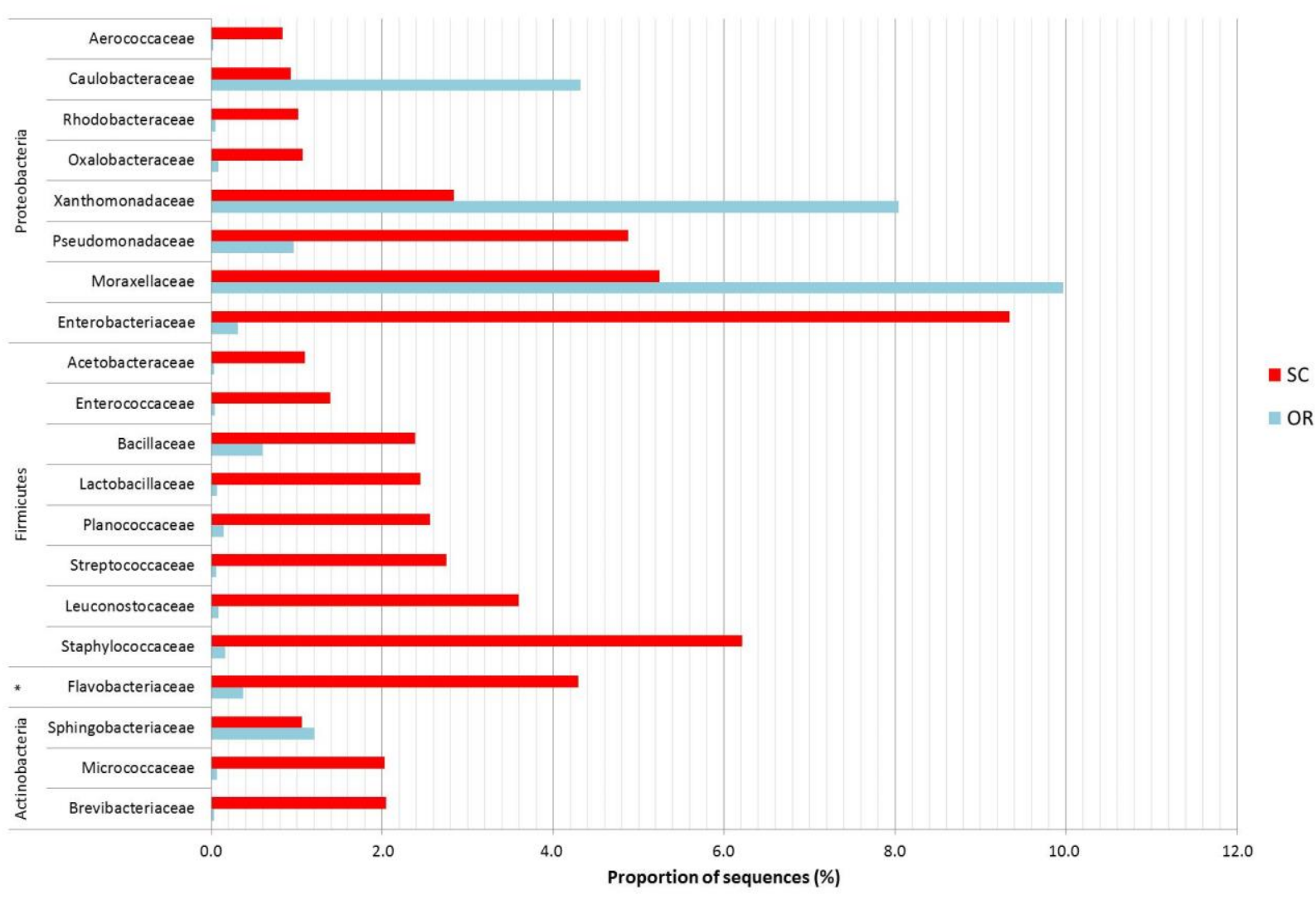

Figure 2: Bacterial biodiversity at the family rank in bioaerosols from the WSP. Bioaerosol samples were collected in the Sorting Cabin (SC) and in the Outdoor Reference (OR). Data are given for the 20 dominant families found in SC samples. For practical reasons, only the mean of sequencing data from $\mathrm{SC} 1, \mathrm{SC} 2$ and $\mathrm{SC} 3$ are presented. *: corresponds to Bacteroidetes. 
A.

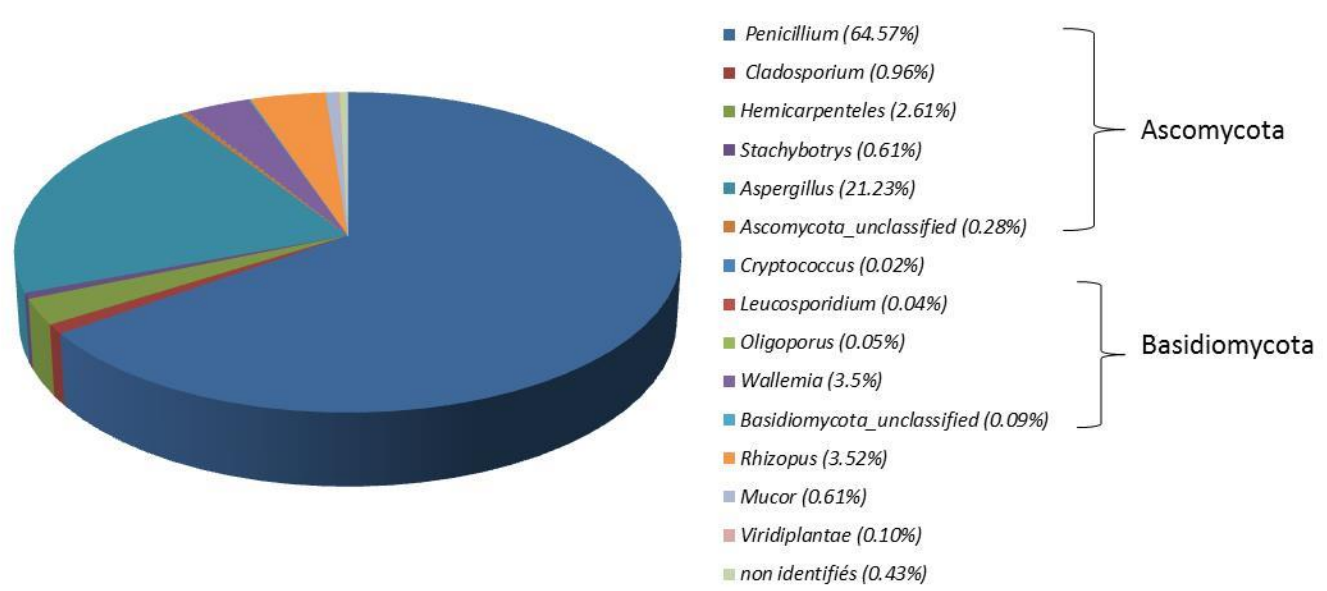

B.
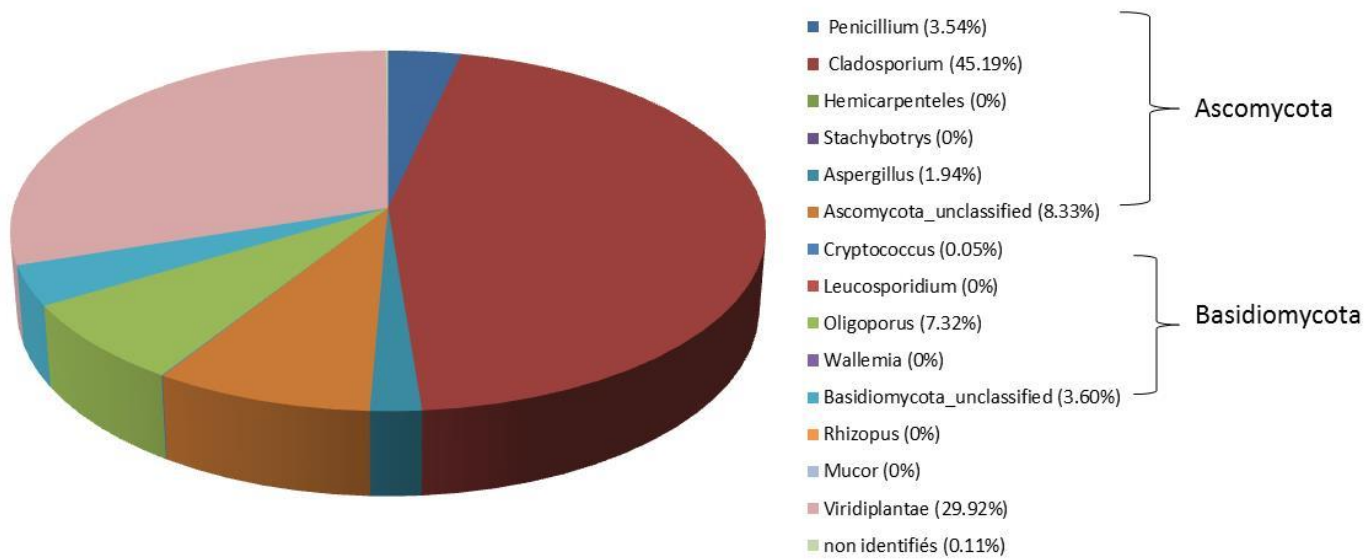

Figure 3: Fungal biodiversity at the genus rank in bioaerosols from the WSP. Bioaerosol samples were collected A: in the Sorting Cabin and B: in the Outdoor Reference. For practical reasons, only the mean of sequencing data from SC1, SC2 and SC3 are presented. 


\begin{tabular}{ccccc}
\hline \hline Parameters & SC1 & SC2 & SC3 & OR \\
\hline Bacterial 16S $\boldsymbol{r D N A}^{\boldsymbol{a}}$ & & & & \\
Number of reads & 100,895 & 100,2115 & 69,655 & 78,603 \\
Number of OTU & 1233 & 1326 & 842 & 581 \\
Number of unique sequences & 218 & 233 & 255 & 262 \\
Simpson's index & 0.02 & 0.02 & 0.02 & 0.1 \\
Shannon's index & 6.43 & 6.60 & 6.41 & 4.24 \\
Eukaryota 18S $\boldsymbol{r D N A}{ }^{\boldsymbol{b}}$ & & & & \\
Number of reads & 14,546 & 16,082 & 21,206 & 6,588 \\
Number of OTU & 38 & 42 & 41 & 15 \\
Number of unique sequences & 3 & 5 & 2 & 1.83 \\
Simpson's index & 0.44 & 0.46 & 0.49 & 0.25 \\
Shannon's index & 1.30 & 1.28 & 1.17 & \\
\hline \hline
\end{tabular}

Table 1: Overview of high-throughput sequencing data obtained from bioaerosol samples taken in the WSP. Bioaerosol samples were collected in the Sorting Cabin (SC) and in the Outdoor Reference (OR). ${ }^{\mathbf{a}}$ : Illumina sequencing; ${ }^{\text {b. }} 454$ pyrosequencing. 